\title{
Paseo escritural de Augusto d'Halmar durante la Primera Guerra Mundial en París*
}

\author{
Jaime Galgani Muñoz**
}

\begin{abstract}
Resumen
Augusto d'Halmar ofició como corresponsal en París durante la última fase de la Primera Guerra Mundial. Lo hizo para los diarios La Unión de Chile y La Nación de Argentina. En este artículo se revisan algunas de las contribuciones del escritor chileno con el fin de observar los rasgos con que se describe el modo de visitar y pasear por la "ciudad luz", intentando resolver, en medio de la guerra y a través de la escritura, la complejidad de su posición de intelectual latinoamericano. El artículo concluye con una alusión a un relato del autor que ofrece, a modo de complementación, los elementos para comprender la visión general del paseante (flâneur) en medio de París.
\end{abstract}

Palabras clave: flâneur, flanerie, modernidad, disidencia sexual, periodismo, Augusto d'Halmar, Arturo Ambrogi.

\section{The writer's Stroll of Augusto d'Halmar during the First Word War in Paris}

\begin{abstract}
Augusto d'Halmar worked as a correspondent in Paris during the last stage of the First World War. He did so for La Unión from Chile and La Nación from Argentina. In this paper, some of the contributions of the Chilean writer are revised with the aim of observing the features with which he describes his visiting and strolling "the city of light", trying to solve, in the middle of the war and though his writing, the complexity of his standpoint as a LatinAmerican intellectual. The paper concludes with an allusion to the author's narration which offers, as a complement, the elements to understand the general perspective of the stroller (flâneur) in Paris.
\end{abstract}

Keywords: Flâneur, Flanerie, Modernity, Sexual dissidence, Journalism, Augusto d'Halmar, Arturo Ambrogi.

Recibido: 18/07/2018

Aceptado: 29/08/2018

\footnotetext{
* Este artículo está asociado al proyecto FONDECYT Regular 1160222. Tiene como base aportes de un artículo redactado para el proyecto 1130400 que jamás fue publicado. El trabajo actual cuenta con aportes de ponencias presentadas en la Universidad de Concepción (2018) y el Congreso de Americanistas 56 (2018), Salamanca.

** Chileno. Doctor en Literatura. Académico Universidad Metropolitana de Ciencias de la Educación (UMCE), Santiago, Chile. Investigador responsable FONDECYT 1160222: "Literatura y periodismo: corresponsables y columnistas de guerra chilenos (1879-1945)”. jaime.galgani@umce.cl
} 
"A guerra terminou ontem mas ainda há batalhas dentro no peito que estáo reclamando herois." (Carlos Drummond de Andrade)

\section{Introducción}

Augusto d'Halmar (1882-1950) llegó a París en medio de la Gran Guerra, con un afán novicio por acercarse a la modernidad europea sin ambages y con una admiración y afán de reencuentro con su ciudad amada que, en momentos, pareciera ser acrítico. El escritor representa la búsqueda del intelectual latinoamericano de aquellos componentes de la modernidad que considera fundantes de la cultura universal. París, para él es la nueva Atenas, la sede de la cultura occidental asediada por los espasmos de la guerra y la brutalidad que representa la amenaza alemana. Su participación como reportero o cronista de guerra resulta, por ello, particularmente distinta a la de otros escritores e intelectuales que se sintieron afectados por los fenómenos bélicos europeos del siglo XX. Sus crónicas revelan más la admiración que siente por "la ciudad luz" que el espanto frente a las amenazas de la guerra. A decir verdad, las inquietantes preocupaciones de una identidad sexual problemática lo acompañaban durante su viaje y, por así decirlo, era otra guerra la que necesitaba combatir: la de su identidad homosexual no resuelta, para la que el conflicto armado de inicios de siglo le serviría apenas de pretexto y de camuflaje. Era otro paseo el que necesitaba emprender o, mejor dicho, ese múltiple paseo urbano, que era también un desplazamiento que se espejaba escrituralmente, era un bucle que continuamente bajaba y subía a y desde la superficie de las calles y sus jardines hasta los rincones de un yo enigmático.

Es interesante ver cómo la posición de d'Halmar en el escenario europeo confiere una serie de dualidades que conviene tener presentes antes de afrontar la cuestión del callejeo impresionista que es el modo propio de la flanerie d'halmariana, la flanerie del observante escritor y cronista que, mirando un mundo desde su posición particular, refleja el encuentro o la tensión entre polaridades que diagraman su condición postcolonial. 1) El escritor y su nacionalidad v/s su ubicación físico-temporal. Un chileno en el París de la guerra. El observante y sus tensiones con el espacio narrado. El cronista-paseante y la ciudad 
de su escena como objeto de deseo. Para un latinoamericano que no pertenece a la oligarquía, para quien ha viajado normalmente gracias a los beneficios de una misión, una legación o una tarea, París es un privilegio. Así pues, en d'Halmar, a pesar de su lenguaje culto, a pesar de su estampa corporal europea, a pesar de su vestuario y sus modelos, su mirada latinoamericana, su asombro y su alegría revelan las huellas de su postcolonialidad; mimicry que no oculta un arribismo que, al mismo tiempo, es ponderación sin límites con respecto a París y amnesia total con respecto a su origen provinciano. 2) Dos modernidades en tensión: la modernidad central europea y la modernidad periférica latinoamericana. D’Halmar solo conoce y asigna valor a la primera. Su preocupación con respecto a la modernidad europea no consiste en traerla a Latinoamérica o a Chile, como sí lo pretendía Alberto Edwards que soñaba con un Chile moderno. D'Halmar, simplemente, va como un paseante modernista a observar la ciudad y sus contingencias. 3) Blanqueamiento. Subalternidad europeizada, asimilación voluntaria por la vía del deseo. D'Halmar, ya había hecho esfuerzos por europeizarse con la elección de su seudónimo y con su narrativa y autopoyética vinculación con un barón nórdico: el barón d'Halmar. El vagabundeo parisiense es la coronación de ese proyecto blanqueador, donde no hay orfandad ni ausencias nobiliarias. 4) Dos espacios discursivos: literatura y prensa. Es el escritor que escribe no un poema, sino una crónica, pero, al hacerlo, pone en tensión sus recursos creativos, su potencia elocutiva, su arte retórica. Y, en la crónica, pone en ejercicio los mecanismos de la modernidad escrituraria: brevedad v/s intensidad comunicativa, impacto noticioso v/s belleza estilística. 5) La ciudad como espacio abierto y sometido a los vaivenes del conflicto armado v/s la intimidad del “cuarto propio". D'Halmar escribe desde un cuarto iluminado por la luz física de una bujía y por la luz inmaterial de la razón, mientras afuera, en la oscuridad, pueden escucharse bombas lejanas o gritos de la gente. París, la ciudad luz, la ciudad de la razón, es más París en el escritorio de d'Halmar que afuera. Mientras haya alguien que piense la ciudad, la observe, la describa, la lleve a la escritura, París vive en la esencia de su naturaleza histórica y social. 6) Presente - pasado glorioso - futuro esperanzador. El tiempo disgregado y crítico del "afuera”, del "pueblo", es ordenado por el escritor, el intelectual, que es el alma racional de la modernidad. 7) El intelectual es en la calle un flâneur y, en la intimidad, un cronista. Dos paseos: el paseo de la ciudad y el paseo interior de la razón iluminada. La polaridad de ambos estados revela la complejidad de 
una misma condición. 8) Las crónicas de d'Halmar, finalmente, revelan la esperanza de la paz sobre la sinrazón de la guerra. Su esfuerzo intelectual no solo tiene valor estético sino también político.

París fue, en muchos aspectos, la ciudad de referencia para intelectuales y escritores latinoamericanos durante el siglo XIX y gran parte del siglo XX. Entre ellos, el escritor chileno Augusto d'Halmar quien, además de referirse a ella en algunas de sus narraciones y retazos biográficos, la escogió como su ciudad definitiva a fines de 1916, en donde ejercería como corresponsal de guerra de los periódicos $L a$ Unión de Santiago de Chile y La Nación de Buenos Aires. Sin embargo, aquella ciudad, que brevemente había visitado en el cambio de año de 1907 a 1908, no pudo transformarse en su residencia sino por un par de años; al concluir la Primera Guerra Mundial, por razones que nunca se han explicado, la abandonó para siempre con destino a Madrid. Las impresiones de su estadía en París son accesibles gracias a la lectura de las crónicas que escribió como corresponsal ${ }^{1}$. En ellas resulta claramente destacable el perfil del sujeto cronista con los rasgos del flâneur decimonónico que ejecuta una flanerie que sigue, de algún modo, los rituales de los paseantes latinoamericanos por Europa. Por este motivo, el objetivo de este artículo consiste en describir algunos rasgos de la flanerie d'halmariana, intentando demostrar que su práctica peripatética sigue las huellas del imaginario parisiense que había elaborado desde sus primeras lecturas, antes de su primer viaje en 1907, cuando pudo comprobar que la cartografía urbana coincidía con el mapa de la ciudad soñada. D'Halmar intenta demostrar, hasta donde le es posible, que la ciudad en guerra sigue siendo la de siempre, la ciudad eterna, la que está más allá de las peripecias contingentes y en donde se quintaescencian los resultados más finos de la Humanidad. Es propósito de este artículo, además, demostrar que su recorrido por París tiene similitudes con el de otro escritor contemporáneo, el salvadoreño Arturo Ambrogi (1875-1936), quien, al decir de uno de sus estudiosos, realiza una flanerie cualificable como "callejeo impresionista". Sin embargo, este callejeo, que bien podría tener las características superficiales de un recorrido que no compromete la intimidad del sujeto, en el caso de la obra d'halmariana se profundiza al considerar sus narraciones, al punto de reconocer que esa flanerie le permite recorrer en la ciudad nocturna el sendero que conduce 
hacia su sexualidad negada. En síntesis, el paseo d'halmariano por París comienza en su niñez, leyendo y viendo fotografías, continúa con su callejeo impresionista y concluye con el hallazgo y el pronunciamiento oblicuo de la otredad sexual.

\section{La flanerie d'halmariana}

Dorde Cuvardic García (2012) ha publicado un extenso estudio que se inicia con la definición del flâneur como "categoría estética y social", por un lado, y la flanerie como "propuesta conceptual en la ciencia social", por otro. Sitúa el flâneur como uno de los diversos "representantes peripatéticos de la modernidad" y recoge las conceptualizaciones de Engels, Simmel, De Certeau y Benjamin. Más adelante, revisa la presencia del flâneur en la literatura francesa (Louis-Sébastian Mercier, Balzac, Baudelaire, Apollinaire, Breton y Louis Aragon), en la literatura alemana (Robert Walser, Franz Hessel y Siegfried Kracauer), en la literatura anglosajona (Egan, Lamb, de Quincey, Dickens, Albert Smith y en exponentes norteamericanos), en la literatura española (Larra y Mesonero Romanos) y en la literatura latinoamericana (Darío, Sarmiento, Gómez Carrillo, y otros). Su completo estudio concluye con una clasificación de distintos tipos de flanerie, identificables según los intereses narrativos o periodísticos de algunos destacados representantes del modernismo latinoamericano: la flanerie de Julián del Casal la define como "callejeo a 'regañadientes"'; la de Amado Nervo, como "periodismo de boulevar"; la de José Martí, como de "elogio a la democracia estadounidense y crítica a su proyecto modernizador"; la de Manuel Gutiérrez Nájera, como "la perspectiva pequeñoburguesa de repudio a la Otredad urbana"; y, finalmente, la de Arturo Ambrogi como de "apertura sensorial al callejeo impresionista" (cfr. 9-12).

Si bien el estudio mencionado no considera el nombre de Augusto d'Halmar, resulta de utilidad la clasificación propuesta por su autor. Lo es porque facilita una aproximación que, comparativamente, ofrece luces valiosas sobre la flanerie practicada por el autor de las crónicas y relatos que tienen como centro a París, y a d'Halmar caminando por él como cronista o a través de sus personajes narrativos. A la hora de buscar semejanzas, se advierte que, ciertamente, el escritor chileno manifiesta, en uno u otro momento, características que lo acercan, en el aspecto que nos interesa, a Julián del Casal, a Amado Nervo, a Manuel 
Gutiérrez Nájera, etc. Sin embargo, es probable que la mayor cercanía se dé con Arturo Ambrogi, un desconocido escritor salvadoreño que, como d'Halmar, se instala en las letras latinoamericanas con ese tono menor que los ha relegado al casi exclusivo interés de académicos y libreros.

Al revisar la biografía de Ambrogi, resulta interesante advertir que no solo en cuestiones temáticas parece encontrarse con el autor de La Lucero, sino también en varias peripecias viajeras y en intereses comunes. Ambrogi nace en El Salvador, en 1875, apenas siete años antes de d'Halmar. Hacia 1896, viaja a Chile para radicarse un poco más de dos años entre nosotros. En ese tiempo, publica en el periódico La Ley, el mismo en donde trabajaba d'Halmar. Posteriormente, viaja a Europa y al Asia. Como se verá más adelante, junto a estas encrucijadas vitales, están las coincidencias y preocupaciones temáticas comunes y, en particular, la visión del viajero en la literatura y en la crónica. Aunque podría pensarse que hubo una relación cercana entre los dos escritores, la única referencia de d'Halmar con respecto a Ambrogi es aquella en que habla de las veladas donde se encontraban artistas de la generación del '900; en efecto, después de listar a los más importantes asistentes, agrega: “... y luego elementos exóticos, más o menos de paso entre nosotros, como Ricardo Brenes Mesén, Arturo Ambrogi, Joaquín García Monge..." (Recuerdos olvidados 121-122). Revisión similar, aunque no tan acuciosa en las obras de Ambrogi, permite afirmar provisoriamente que el salvadoreño no considera para nada al que seguramente fue su compañero de tertulias y de sala de redacción; quizás el todavía no ostensible protagonismo de d'Halmar podría ser la causa de ello. Ahora bien, si dados estos antecedentes, no se puede sostener una influencia recíproca, sí se colige que respiraron el mismo aire intelectual, similares influencias, preocupaciones y lecturas. Era el aire del '900, el de entresiglos, el que Ambrogi vino a buscar a Santiago de Chile, por entonces metrópolis intelectual latinoamericana. Era la atmósfera del modernismo y su espíritu epocal que lo impregnaba todo. Era el clima favorecido por la vitalidad de los artistas e intelectuales latinoamericanos que miraban con admiración los vientos que venían de la metrópolis moderna que era, por excelencia, París.

Retornando al tema central, el propósito siguiente consiste en seleccionar, siguiendo el estudio de Dorde Cuvardic García, las características generales de la flanerie de Ambrogi, calificada por él como de "callejeo impresionista" y, de este modo, establecer comparativamente 
los rasgos de la flanerie d'halmariana para, así, iniciar el recorrido del escritor chileno por París a través de sus crónicas.

En primer lugar, Arturo Ambrogi “[u]tiliza el término 'sensaciones' en sus crónicas sobre culturas extranjeras, que Gómez Carrillo también emplea en esa misma época" (421). Esa estética impresionista es posible verla también en d'Halmar; ejemplo de ello son las crónicas que clasificó bajo el título de "Peregrinas" e "Iniciaciones" y que publicó en el periódico Informaciones en Madrid, a partir de 1926, así como el hecho de haber trabajado a comienzos del '900 en el periódico de sugerente nombre Instantáneas de luz i sombra. Sus mismas obras, en algún caso, tienen títulos que recogen la dinámica evasiva y sugerente del impresionismo; así, por ejemplo: La sombra del humo en el espejo (1918). De este modo, el andar d'halmariano persigue, más que informaciones exactas sobre la realidad, las "sensaciones" que buscaban otros escritores latinoamericanos en sus viajes; el hálito de la muchedumbre, el olor de los mercados, las impresiones sensoriales del movimiento y el hervor de las ciudades.

En segundo lugar, en algunas de sus obras, Ambrogi “ocasionalmente emplea la flanerie como procedimiento que le permite observar y describir la cultura oriental" (422). Destaca, en esos escritos, "el desengaño, el incumplimiento de las expectativas culturales" (422). Para el caso de d'Halmar, la cultura oriental es un tema gravitante, quizás más para su narrativa que para sus crónicas y también, en algunos casos, se advierte una frustración con respeto a sus expectativas (la descripción de Calcuta es la más emblemática). Sin embargo, las decepciones del salvadoreño y del chileno son distintas. El primero se siente molesto por la occidentalización de las ciudades que describe (Tokio, por ejemplo); el segundo, en cambio, manifiesta un íntimo escozor frente a la incomodidad que le provoca el calor, el desorden, los ruidos, la humedad... La flanerie de d'Halmar por la India está marcada por el estupor que le provoca no tanto la otredad oriental, sino aquella otredad ineludible, es decir, la íntima, la interior, la de saberse un sujeto extraño y menos adaptable de lo que había pensado en sus ensoñaciones desde casa.

En tercer lugar, Cuvardic García señala en Ambrogi una cuestión propia de los viajeros de entonces, que es la tensión que sufre el cronista "entre la actitud de adoptar el papel de turista y el de repudiarlo" (422). Este tópico, propio de otros escritores modernistas (Gutiérrez Nájera, por ejemplo), se relaciona con el lugar que el hablante quiere tener 
frente a la multitud. Se verá, más adelante, cómo d'Halmar claramente establece una diferencia entre el tipo de paseante que es él y los demás. Él es el paseante-pensante, reflexivo, nimbado por el aura aristocrática de los que pueden pasear entre el ruido y la muchedumbre sin quitarle a su soledad ninguno de sus privilegios y sin ser confundidos jamás con un turista.

En cuarto lugar, también como en otros modernistas, aparece en las obras de Ambrogi "[1] a mirada desde la ventana (por lo general desde la habitación del hotel) en los primeros momentos de llegada al país", procedimiento muy utilizado por "los viajeros latinoamericanos en Europa" (422). De este modo, el viajero-observador objetiva su posición frente a la nueva ciudad. Al respecto, Cuvardic García se extiende con el fin de dar cuenta de este recurso como "común en la literatura de viajes" y cita los ejemplos de Alberto Moravia y Paul Theroux, quienes tienen en común el hecho de que "condenan y trivializan el objeto de su mirada, entrevisto como espacio de fealdad y desorden" (422). Tratándose de escritores latinoamericanos, ofrece amplias referencias con respecto a Gómez Carillo. D'Halmar no es una excepción. Un ejemplo: en la crónica "Vagando por París" (1917) dice: “[e]n esa primavera del día, que se llama mañana, y en esa mañana del año que es la primavera, he arrimado mi mesa contra el balcón y a través de los cristales veo el Sena y estos viejos muelles...".

En quinto lugar, coincidiendo con un punto señalado anteriormente, en el caso de Ambrogi no se vería el tipo de exotismo de Pierre Loti, el cual, junto a Lafcadio Hearn, presenta un Japón "divinizado" que no responde al occidentalismo que hace de aquella visión exotista una imagen agonizante, "que se va, sin remedio" (Citado por Cuvardic García, 422). Este aspecto, sin duda, señala una nota diferenciadora entre el exotismo de Ambrogi y el de d'Halmar puesto que, si bien es cierto que el escritor chileno no deja de señalar su mirada crítica frente a los basurales, las molestias del clima, la abundancia incontrolable de turistas, siempre se lo ve en la búsqueda de un remanente exótico que, en definitiva, termina siendo un rescate del imaginario previamente forjado especialmente con las lecturas de Loti.

En sexto lugar, en algunas de las crónicas de Ambrogi -en total coincidencia con d'Halmar- se observa "la mirada predominante del flâneur de los bulevares". El interés por "el movimiento de la enorme ciudad". En dichos pasajes, "[i]mpera la estética impresionista, la 
atracción hacia la modernidad de las superficies reflectantes, las luces, los escaparates..." (423).

En séptimo lugar, en ocasiones, el cronista de Ambrogi realiza una flanerie en rickshaw (423), es decir, movilizado en un vehículo tirado por una persona, una bicicleta o motocicleta, lo que le permite ver la ciudad estando dentro de ella, pero al mismo tiempo fuera. Sería una extensión del recurso consistente en ver “desde la ventana”. Una variación de este mecanismo se ve en algunas de las crónicas parisienses de d'Halmar; por ejemplo, al desplazarse hasta Versalles en tren o, en un día de paseo, navegando el Sena en un bateau mouche, e incluso, extremando la analogía, cuando se sube a un avión militar para observar ya no la ciudad sino "el mundo" desde arriba.

Un octavo elemento de la flanerie de Ambrogi consiste en que, a veces, el cronista se hace acompañar por un guía (423). Este recurso es utilizado por d'Halmar sobre todo en su viaje a Oriente; no lo vemos en París. Incluso valga destacar que, en la crónica "Vagando por París", indica que prefirió salir solo en su primer recorrido, evitando al amigo que descansaba en otro cuarto y que pensaba que el recién llegado se encontraba durmiendo.

Una novena característica común para Ambrogi y d'Halmar es la observación de los espacios de la muchedumbre: el mercado, las tiendas, los paseos. La observación de la ciudad contempla algunos rasgos típicos de la mirada del flâneur en el sentido de señalar "los cambios en la modernidad social y cultural"; así lo hace Ambrogi, por ejemplo, en su crónica “Los ruidos de San Salvador" (424). D’Halmar hará lo propio en una crónica que titula "Los ruidos de Madrid” (Informaciones, 1927). Tanto el flâneur de Ambrogi como el de d'Halmar se detienen en las nuevas dinámicas que alteran el dinamismo de la antigua ciudad con el advenimiento de las masas y de la modernización.

Finalmente, no falta en Ambrogi la mirada al "jardín urbano", ampliamente coincidente con d'Halmar. Así, por ejemplo, ambos tienen crónicas donde aparecen sus recorridos por los Jardines de Luxemburgo (424). El jardín es la heterotopía recreacional del flâneur; ese es, al decir de Ambrogi, el espacio "propicio a la meditación y al reposo en medio del sacudimiento matinal de París [...] reposo para mis retinas fatigadas, extenuadas, por el incomparable desfile de visiones" (ctd. por Cuvardic García 424). 
En síntesis, descrito el tipo de flâneur que presenta Arturo Ambrogi en diálogo con la práctica d'halmariana, es posible perfilar también al flâneur del cronista chileno con las características del "callejeo impresionista". Se trata de un observador que recorre y describe la ciudad y sus espacios, recogiendo percepciones visuales, auditivas, táctiles y olfativas, al mismo tiempo que tratando de leer, en cada uno de los monumentos, jardines, museos, bulevares, etc., la información letrada que lleva a cuestas. Ya sea desde una ventana, desde un tren o un barco, acompañado o solitario, el paseante d'halmariano se distingue y separa de la multitud. Su flanerie es aristocrática y, al mismo tiempo, es intelectual y sensorial. Cuando se trata de los viajes a Oriente, sin embargo, Ambrogi y d'Halmar se distancian, pues el autor chileno hace prevalecer como imaginario el exotismo de Loti que, según el cronista salvadoreño, no prevalece sino en la literatura.

\section{D’Halmar en París: de "vagamundos" a "paseante"}

De los tres grandes períodos en que se divide la biografía de Augusto d'Halmar (1882-1950), el segundo, que va desde 1907 a 1934², consistió en un largo periplo que lo llevó a diversos lugares. La permanencia en ellos fue irregular y no siempre suficientemente documentada. "En 1916, hace [un] breve viaje a Chile, después de ocho años y meses de ausencia", según testimonian Arriagada y Goldsack $(1963,39)$, retomando posteriormente su largo viaje, esta a vez a París y, por su propia cuenta, pues, por razones que nadie ha explicado, durante su paso por Santiago de Chile es desvinculado del cuerpo diplomático; sus intenciones entonces son las de no regresar más a su patria de origen: "Justamente agraviado por el Ministerio de Relaciones Exteriores, que lo ha separado de la carrera consular, sin atender a sus extraordinarios méritos literarios y administrativos, cae en una crisis de violento antipatriotismo" (Arriagada y Goldsack 39).

El lapso de su vida parisiense no logra determinarse con precisión, pero se puede colegir que, habiendo llegado durante la primera mitad de 1917, cambió nuevamente de residencia (esta vez a Madrid) a fines

\footnotetext{
La biografía de d'Halmar se divide en tres grandes períodos: 1882-1907 (niñez y juventud en Chile), 1907-1934 (errancia en diversos países), 1934-1950 (residencia en Chile hasta su muerte). Así, su vida está distribuida en tres períodos de 27, 27 y 16 años.
} 
de 1918 o principios de 1919. Aunque algunas fuentes poco confiables lo sitúan viviendo, después de París, en Buenos Aires, los datos que consignan los críticos más arriba citados permiten concluir que, entre París y Madrid, no hubo destino intermedio:

Se encontraba escribiendo el 11 de noviembre de $191[8]^{3}$, cuando lo sorprendió la noticia del armisticio [término de la Primera Guerra Mundial]. Después de sumarse, por algunas horas, al júbilo general, hizo sus maletas y pasó a España, en donde habría de radicarse hasta principios de 1934, fecha en que la nostalgia del solar patrio lo trajo a Chile, de donde no volvería a salir más. (42)

Tanto los testimonios críticos como las propias palabras de d'Halmar (según se verá en las siguientes páginas) permiten afirmar que su destino final, el más añorado, era París. Ahora, en la segunda etapa de su gran viaje, liberado de los compromisos diplomáticos, pudo, al menos por un período, cumplir con la aspiración común a muchos intelectuales latinoamericanos de escoger como residencia la "ciudad luz". Lo ayudó, sin duda, la doble destinación que recibió como corresponsal de guerra en dicha ciudad para los periódicos La Unión de Santiago de Chile y La Nación de Buenos Aires.

Meses después de llegar a París, comienzan a publicarse las primeras crónicas que envía a La Unión. En una de ellas, bosqueja literariamente su condición de viajero resumiendo los recorridos realizados hasta entonces:

En materia de vagar, ¿quería yo recordar mis vagabundeos interminables por todas las ciudades de ensueño a las cuales ha ido conduciéndome la realidad? Viajero en Italia, buen musulmán en Turquía, beduino en Egipto, peregrino en la Tierra Santa, desterrado de mí mismo en la India abrasadora, ausente de mí mismo en las tierras peruanas, hijo pródigo de la España solariega. ("Vagando por París")

Sin embargo, esa condición de viajero cosmopolita, de "vagamundo" -ya reconocida por quienes seguían sus noticias desde Chile- no era su interés mayor en el texto citado. Lo que quería recordar era, en cambio, la primera vez que visitó París:

Arriagada y Goldsack cometen un error al decir que la fecha de ese armisticio fue el 11 de noviembre de 1919 . 
“... yo deseaba evocar, únicamente, mi primera impresión de París hace ya tantos años y compararla y comprobarla con la que experimento cada día, ahora que la ciudad única es mi sorpresa cotidiana" ("Vagando por París"). ${ }^{4}$

La necesidad de ese recuerdo y los contenidos del mismo, consignados en esa crónica, resultan particularmente importantes para afrontar la pregunta sobre cuál es, en primer lugar, el París que d'Halmar esperaba encontrar cuando lo visitó por primera vez, comparándolo con el que era en 1917, durante la Gran Guerra, y, en segundo lugar, el posicionamiento subjetivo que él mismo cree o espera tener frente a la ciudad pensada, soñada, imaginada. De este modo, se pretende comprender en qué medida el escritor, corresponsal, periodista, pasa de identificarse como un viajero universal a un paseante de la ciudad y, así, verificar la posibilidad de atribuir a su proyecto vital las categorías del flâneur decimonónico de que hablaba Baudelaire y que, posteriormente, formuló Walter Benjamin.

\section{"Vagamundos, vagabundos y vagos"}

Así titula d'Halmar una crónica que publicó en Informaciones, periódico madrileño, con fecha 17 de junio de 1930. Lo hace para comentar la próxima realización de un "congreso de vagabundos" en Viena (agosto del mismo año). En ella opone "los hombres civilizados y gobernados, los hombres de orden", a aquellos que "sin trabas y sin férula, no sólo son fuertes, no sólo son sanos, sino que también son bellos y, sobre todo, son alegres, habiendo conservado ese loco cascabel de la alegría, que no puede sujetarse a ningún badajo". Coincidente en algunos aspectos con esa apología del vagabundeo", su crónica "Vagando por París", ya citada anteriormente, comienza con la clasificación de dos tipos de viajeros:

Hay espíritus precisos para los cuales las palabras vagar y divagar no tienen sentido... ni aplicación. En la ciudad que habitan,

Más tarde precisará que la fecha de la llegada a la capital francesa en ese primer viaje fue la de la noche que va del 22 al 23 de diciembre de 1907, poco después de su salida de Chile con rumbo a la India en un itinerario que contemplaba inicialmente "Liverpool, Londres, París, Marsella, Nápoles, Alejandría, Puerto Said, Bombay y Calcuta" (Arriagada y Goldsack 36).

5 Está claro que el uso que d'Halmar da a la palabra "vagabundo" se parece más al de flâneur que al de quien camina por la ciudad en búsqueda de limosna. 
saben perfectamente el tranvía que deben tomar y a qué horas deben tomarlo. En viaje, esos mismos espíritus prácticos saben con igual concisión el tren y la hora del tren. [...] y no hay cuidado que se permitan ninguno de esos caprichosos desórdenes de la fantasía que para otros, para mí, pongo por caso, constituyen la verdadera y única diversidad del mundo y de la vida. ("Vagando por París")

El buen burgués, ordenado y metódico, no conocerá las sorpresas en su viaje. En cambio el otro, el vagamundos, peregrina sin mapas ni almanaque. D’Halmar se reconoce en ellos: “Yo he vagado y, ¡Dios mío! he, sobre todo, divagado conmigo mismo y fuera de mí, adonde quiera que me han llevado mis pasos..." ("Vagando por París"), teniendo por única estrella la voluntad azarosa del destino:

y Dios sabe también que, por muy inesperados que hayan sido [mis pasos], calculados estaban y determinados por ese mentor invisible que los más escépticos llaman todavía destino $^{6}[\ldots]$ Cuando se aprende de aquella verdad, uno se abandona confiadamente a eso que también llamamos azar, y se deja uno marchar como cuando se era pequeño, como si otra gran mano nos condujese. Así he vagado y he divagado yo. ("Vagando por París")

Siguiendo el curso de esta primera crónica de d'Halmar en el París de la Gran Guerra, conviene detenerse para captar las impresiones que recuerda de su primera visita a la ciudad (23 de diciembre de 1907). En primer lugar, su fidelidad a las fuerzas misteriosas que lo llevaron hasta allí: "Hacía muchos años que había pactado ese viaje con esas potencias ocultas que podríamos llamar servidoras de la voluntad...”. En segundo lugar, su identificación con esa cofradía universal a la que se siente pertenecer: “... yo me eché también a la calle para gozar el incompartible triunfo de reconocer, de verificar ese París que nos es casi familiar a los intelectuales de todas las razas y las tierras". En tercer lugar, el encuentro

Está pendiente un estudio sobre el significado de la palabra “destino” para D’Halmar. Dicho sea, simplemente que, para él, confeso seguidor de la doctrina llamada "fatalismo", el destino no es una palabra coloquial que resume o simplifica las cuestiones relacionadas con el futuro esperable o temible, sino una convicción estoica de que nada se puede hacer en contra de lo que ya se ha diseñado para la suerte de cada persona individual. En su crónica “Volando", también escrita en París (1917), ante la incertidumbre natural que sintió la primera vez que subió a un avión, expresa: “Cuando ni se espera ni se teme, cuando se ha aprendido que no puede suceder sino lo que debe, todo coraje o todo temor son simplemente inútiles. Ya no se es ni poltrón ni héroe, puesto que basta con ser lo que se es: el hombre y su destino". 
pactado entre su deseo de caminante lejano y el símbolo principal de la ciudad: "Momento inolvidable en que acudíamos a la cita, yo el forastero, desde los límites del mundo y ella, la Catedral [de Notre Dame], desde la profundidad de las edades". Finalmente, su inscripción viajera en la línea de los paseantes de la modernidad: “... yo deambulaba, como si realmente lo hiciera en sueños, entre la muchedumbre nocturna de los boulevares (sic)" ("Vagando por París").

El recorrido de aquella primera visita lo llevó desde el Teatro Odeón hasta los Campos Elíseos, pasando por el frontis de los Jardines de Luxemburgo, la calle Racine, el boulevard Saint Michel, el Sena, la Catedral de Notre Dame, el muelle del Reloj, la puerta de Saint Denis, la Place Vendôme, etc. Si ha de hacerse caso a su convicción casi religiosa, lo llevaba el destino. En términos prácticos, lo conducía el mapa mental que había elaborado gracias a las fotografías que había visto y a las lecturas realizadas. Pero, en definitiva, era una voluntad antigua, labrada desde su infancia, la que hacía de ese paradero un destino profundamente anhelado: "Y es que en realidad, mis respetables espíritus prácticos, el muchacho criollo venía soñando desde su infancia todas esas realidades, porque hay que soñar mucho para llegar a ver encarnarse algunos de nuestros sueños" ("Vagando por París").

El flâneur de d'Halmar se ajusta, en términos generales, al que se reconoce en las lecturas más clásicas sobre el tema. Es quien "deambula ociosamente por la ciudad, recorre sus bulevares y pasajes, y en ellos vive la experiencia de la multitud en soledad" (Oróstegui 60). Es el observador peripatético que realiza "una trayectoria sin rumbo fijo por la ciudad" (Cuvardic García 404). En ese caminar, actualiza constantemente la síntesis entre la experiencia privada y la colectiva (cfr. Oróstegui 60), es decir, entre lo que viene del mundo circundante revelado como "experiencia" y la materia primordial de las propias expectativas, lo que d'Halmar llama "sueños". De este modo, se configuran las nuevas posibilidades que, en el contexto de la modernidad, todavía tiene la narración?

"En la figura del flâneur se encuentra a otro lector de la materialidad significante. En su encuentro con la masa, se imprime una emoción y una imagen en su memoria; es el narrador de los shocks, así constituyéndolos al mencionarlos. Es en este sentido que Baudelaire define al shock como un "caleidoscopio dotado de conciencia" (Benjamin 44). Al flâneur la realidad se le presenta como espectáculo. En el flâneur confluyen la experiencia colectiva y la privada, por eso también puede ser un narrador." (Oróstegui 6o). 


\section{Modernidad, modernización, normalidad y crisis}

El cronista d'halmariano continuamente hace presente su conciencia de pertenecer a una época de cambios. Su espíritu, a veces decadente en otras narraciones, se muestra, sin embargo, entusiasta frente a la dinámica del progreso, de la máquina y de las posibilidades que suponen para el hombre. Le entusiasma el trabajo, el movimiento de las fraguas y de los hombres que impulsan, con humana fuerza, la fuerza de las maquinarias. $Y$ en ese dinamismo participan todos los quehaceres, incluso el del que divaga:

Veo, pues, trabajar París mientras yo mismo trabajo, o divago, como precisaría el espíritu preciso y precisor; los desembarcadores del río hacen funcionar las gomas, empujan las barcas, gobiernan el movimiento y yo los miro y siento como si otro trabajo casi semejante se cumpliese dentro de mí. También hay en nuestro interior maquinarias que bajan y levantan pesos; también hay hombres, varios, muchos, que se afanan, también un río invisible lleva hacia el mar las barcas... ("Vagando por París")

Dice "trabajo o divago", pero, en realidad, en la modernidad urbana, el trabajo del flâneur es divagar ${ }^{8}$. D'Halmar, complementario de sí mismo por ejercer la doble función de observar la ciudad "desde su ventana" y escribir sus crónicas por las que le pagan, se hace, a la vez, complementario de ese otro tipo de hombres, los que mueven los engranajes del movimiento. Los "desembarcadores del río" representan la imagen hercúlea de hombres que, al mismo tiempo de resultar atrayentes eróticamente ${ }^{9}$, constituyen el símbolo de la tenacidad humana que, acompañada de las máquinas, conducen a la Humanidad hacia su progreso. Análogamente, en el interior de la habitación, hay otros que mueven la maquinaria del pensamiento.

"El flâneur deambula ociosamente por la ciudad, recorre sus bulevares y pasajes, y en ellos vive la experiencia de la multitud en soledad." (Oróstegui 6o).

El imaginario erótico asociado a estibadores, cargueros, bomberos, marineros, etc., no resulta totalmente extraño ni a la estética homoerótica d'halmariana ni, en general, a diversas corrientes propias de la modernidad. Se trata de la fascinación distante que produce la otredad inscrita en los cuerpos que aparecen señalados sublimadamente como objetos de deseo. Aunque escritas posteriormente, estas imágenes recuerdan las palabras de Benjamín Subercaseaux sobre los "cargadores de la Vega, medio desnudos, haciendo alarde de su musculatura vibrante bajo la carga enorme o la "cuna" repleta de frutas" (Subercaseaux 122). 
Sin embargo, la modernización ofrece a la mirada de d'Halmar una posibilidad de ver más alto. En efecto, pocos días antes del 14 de julio de 1917, tuvo la oportunidad de sobrevolar algunas regiones de Francia. El avión suscitaba, todavía, la doble sensación del espanto y de la fascinación, pero respondía simbólicamente a la referencia mítica de Ícaro y a las posibilidades del ser humano de superarse a sí mismo: "Volar! Esa sola palabra que ha tan pocos años era sinónimo de imposible para el hombre, conserva aún y creo que conservará siempre su prestigio casi peligroso" ("Volando"). Parece ser, a los ojos de d'Halmar la culminación del gran sueño de Leonardo, quien precisamente se instala en los inicios de la primera modernidad: "Un nombre acude a nuestra memoria y a nuestros labios cuando nos vemos próximos a realizar el sueño de tantas generaciones de Icaros ( $\mathrm{sic}$ ) y es el de ese iluso, más grande por sus sueños que por sus enormes realizaciones, que se llamó Leonardo da Vinci..." ("Volando"). Esta experiencia de la superioridad humana, puesta en evidencia por la modernización, lo lleva a formular un optimismo casi nietzscheano que pareciera abrir posibilidades de crecimiento sin límite: “y yo sonreí a mi vez, sabiendo como él [el piloto] que todo es pasmosamente sencillo para el hombre que sabe que no es sino un hombre, es decir, casi un dios, mejor dicho, un hombre en el poder de Dios" ("Volando"). No obstante, d'Halmar no se refiere a todo ser humano, pues, en la misma crónica, hace ver su eurocentrismo marcado, muestra clara de la postcolonialidad latinoamericana al referirse a razas indígenas o africanas o, en general, a los híbridos subalternos derivados del mestizaje. Lo hace cuando comenta que, en Perú, durante 1910, había tenido la posibilidad de presenciar unas acrobacias aéreas realizadas por el italiano Rapini, “... rodeado de un pueblo de indios y negros, de pequeños pulperos que no habían salido y que no saldrían nunca de su agujero, y de criollas casi de harem, que lo ignoraban todo de la vida y del progreso..." ("Volando"). Estas valoraciones encajan con las características de la modernidad latinoamericana decimonónica, aquella que mira hacia el mundo europeo ilustrado con fascinación, sin encajar aún las preocupaciones sobre nuestra compleja identidad: “[s]u afán modernizador [el del positivismo del siglo XIX] llegaba hasta el extremo de desconfiar de los propios elementos radicales constitutivos indígenas y negros porque supuestamente no tenían aptitudes para la civilización" (Larraín 314). Así, el flâneur latinoamericano que representa d'Halmar en estas crónicas lleva la marca de la admiración acrítica hacia el sueño 
de la modernidad europea, la que, remontando el vuelo como un nuevo Ícaro, puede regresar a la tierra sin ver derretidas sus alas por el sol; es decir, el hombre en la frontera de su próxima divinización.

La modernidad parisiense para d'Halmar se manifiesta también en los rasgos que confieren estabilidad a la grandeza de un país y de una ciudad. Así, por ejemplo, cuando comenta las prácticas musicales de París, junto a los "versos sentimentales sobre viejos aires conocidos [que el pueblo recita], lo que aquí se llama "la chanzón" (sic), un grupo no muy extenso pero escogidísimo, vive de la religión de la alta música" ("El París musical"). La superioridad cultural de la ciudad ilustrada es que, estando constreñida por el enemigo, no cae "aún en esta época de horror y canibalismo" ("El París musical") en las clásicas exclusiones de los pueblos bárbaros, sino que "[e]n todos los programas franceses, la música alemana ocupa el rango de honor que ocupa en realidad en el mundo" ("El París musical"). Así, d'Halmar, nombrando a Beethoven, Schubert, Schumann, Hayden, Haendel, Weber, Brahms y Bach, de alguna manera desmiente el mito del chovinismo francés; al contrario, París es la ciudad universal que no cambia sus valoraciones supremas por contiendas presentes, por muy graves que ellas sean.

En otras partes, la estabilidad parisiense es vista por d'Halmar como rutina, casi como un signo de conservación que pareciera atentar contra las modas y crisis de la modernidad: “... a medida que comparto el día a día de este París, centro de todas las miradas, me convenzo más y más que, en pocos lugares de la tierra subiste, como en este, la monotonía de la rutina, una rutina no solamente aceptada, sino conservada entretenida y preservada contra cualquier emergencia." ("Una existencia parisiense").

$\mathrm{Y}$ es que, al margen de los grandes protagonistas, de los grandes árboles de la cultura francesa, hay un sotobosque cultural sostenido en el valor de la tradición, empeñado en hacer de París la ciudad eterna: “... este eje de la civilización se aferra más que tu lejano rincón [dirigiéndose al lector chileno] a las tradiciones, como si así tratara de darse, en medio del vértigo de todo lo frágil y efímero que es todo, y que vemos todos, la ilusión de la durabilidad." ("Una existencia parisiense").

En la misma línea, d'Halmar, preocupado de mostrar evidencias de la serenidad de París en medio de la guerra, procura mostrar la tranquilidad al interior de los hogares: 
Cada vivienda, más o menos humilde, más o menos antigua, testifica, pues, la comodidad tradicional del hogar francés. Y pensarlo era prepararse por contraste a la visión de devastación que nos esperaba como objeto de nuestro viaje. ("El hogar y la guerra I")

A pesar de la guerra, que pesa como una pesadilla, se experimenta una impresión de refinamiento cuando abandonando París, por una tarde de primavera, se dirige uno a Versalles... ("Desde París")

Una sensación de vida normal y cultísima nos alivia por un momento de las angustias de la hora y se conversa en el expreso, entre intelectuales, y hombres de mundo, casi como si dos civilizaciones no estuviesen tratando de forzar a cañonazos las puertas del porvenir. ("Desde París")

Admirable esta vieja civilización que entre todos los sacrificios, todavía rinde culto a sus hábitos y conserva la alegría necesaria para cantar refranes de antaño. ("Desde París")

... lo que constituye la fuerza de este país son esta rutina y esta aparente despreocupación. La muerte no interrumpe aquí la vida y no hace, en suma, sino aumentar su sabor. ("Desde París") ... apresurémonos a agregar que la guerra no ha cambiado en nada... ("El París de la guerra")

La vieja ciudad se renueva incesantemente, nada la cambia y todo la modifica y repercute en ella. ("El París de la guerra")

Sin embargo, a pesar de los esfuerzos del cronista por insistir en que París no ha cambiado a pesar de la guerra, que sigue siendo prácticamente la misma que él conociera, debe reconocer que la crueldad bélica, en conjunción con la hostilidad de la naturaleza, han precipitado sobre la ciudad etapas de dura crisis; sobre todo en el invierno que va entre 1917 y 1918 (cfr. "El frío de París"). Pero el triunfalismo d'halmariano vuelve a campear llegado el verano, por lo que, por el momento, el caminante tiene pretextos para volver a encantarse con el vuelo moderno de París hacia el progreso y el triunfo ${ }^{10}$. Lo hará transitoriamente, puesto que, años

1o Materia de otro artículo será la reflexión sobre la crisis moderna en el París de la guerra según Augusto d'Halmar. 
después, cuando redacte sus Recuerdos olvidados (1975), dirá que, con Rafael Valdés, su compañero de viaje,

vio ese París de 1908, es decir, en su momento de oro, cuando París, como la agave, dio su única flor de siglos, antes de desaparecer, dejando también su fino recuerdo olvidado, el aroma de una grandeza desvanecida, y una obra exquisita, que injustamente recaerá, quién sabe en el olvido, ¡la inolvidable ciudad de las ciudades! (396)

\section{El alma encantadora de París}

Algunas ciudades como Roma necesitan, para hablar de ellas, de la precisión de un "arqueólogo y enciclopedista; para hacerlo de París es preciso haber vibrado con todo lo que hace vibrar nuestra época" ("El París de la guerra"); "ser parisiense es como era en la antigüedad ser ateniense" ("El París de la guerra"), porque, en los tiempos modernos, en París "se resume y se pone en limpio cuanto ejecuta la humanidad" ("El París de la guerra"). En esa ciudad que, en el contexto de la guerra, se "juega para siempre su supremacía y con ella la del mundo latino" ("El París de la guerra"), se puede contemplar "[l]a gran poesía y la realidad a la vez de esta vieja Europa [que] es la vejez de todo lo que nos rodea" ("Nuestra Señora de París"). La ciudad escogida por d'Halmar representa incluso la belleza que se manifiesta en medio de la crueldad del frío:

Desde entonces [la noche de Navidad] la sorda blancura no ha hecho sino espesar. Los grandes hombres de las estatuas aparecen revestidos de armiño. Las fuentes parecen colosales compoteras de sorbete y los paseantes mismos, sobre el arroyo tapizado de raso, entre las viviendas enguirnaladas de arabescos níveos, los mismos paseantes parecen, cubiertos de confettis (sic), haber jugado un festival fantasmagórico. ("El frío de París")

O el encanto que tienen los jardines para el habitante parisiense que puede captar los olores y colores que están vedados al extranjero:

A París [...] se lo recuerda por esos jardines, y en este despuntar del Otoño es como un rayo de sol para el crepúsculo de la vida ir a ver amarillear las hojas en esos rincones tan característicos de la gran ciudad y que el extranjero no consigue distinguir, con 
el sello particular de cada uno, sino cuando ha llegado a convertirse en un parisiense cualquiera. ("Los jardines de París")

Conocer esa París solamente es posible cuando se arriba a la percepción ínfima de que "para cada estación del año y cada hora del día, hay un rincón más favorable que otro, que hay que ver en cierta temperatura y a la luz de ciertos momentos, pequeños refinamientos inocentes..." ("Los jardines de París"). Estos son los detalles que caracterizan al flâneur d'halmariano, no un turista, no un erudito de la ciudad, sino un espíritu sensible guiado por la observación azarosa y capaz de percibir las señales "que demuestran que nuestra alma ha llegado a identificarse con lo que un cronista patchouli ha denominado: 'El alma encantadora de París'” (“Los jardines de París”).

Se alcanza aquí un aspecto clave de la reflexión con vistas a comprender el sentido más profundo del callejeo d'halmariano. No quedan dudas ya en cuanto a sus reales intenciones con respecto a París. Su oficio de corresponsal de guerra es apenas un pretexto. Lo que le interesa es profundizar en la conexión personal del sujeto con aquello que llama "el alma encantadora de París". Se trata de la ciudad no como un objeto susceptible de simple narración, sino de ella como espacio de la consumación subjetiva de una relación que busca plenitud. La ciudad no es simplemente un accidente periférico más entre las circunstancias vitales del sujeto, sino el "sueño" que, elaborado desde la infancia, lo ha llevado ahí por artificio de la buena maga fatal del destino para hacer de su vagar una oportunidad creciente de conocimiento y de compenetración personal. Los alcances de esta dimensión superan las crónicas d'halmarianas y es necesario acudir a sus narraciones para valorarlos como corresponde, en concreto "Dariel o El alma en pena de la muchedumbre", parte de una colección de cuatro relatos titulada Los alucinados (1935).

En dicho relato, el teniente de la marina Cristián Davis, alter ego de Augusto d'Halmar, se encuentra sobre la cubierta de su barco en una noche de guardia, después de haber conversado con sus camaradas sobre los recuerdos que tenían de París. El personaje, hombre ya en las cercanías de la edad mayor, solitario frente al mar, motivado por la conversación previa, pronunciaba el nombre de París, "ese nombre de cinco letras, que pudiera ser Babel, y que en tierras y mares galvaniza o hipnotiza a los que lo oyen" (12). Allí, concentrado en sí mismo, permitía decirse lo que sentía con respecto a París y lo que había omitido en su charla con los contertulios. Como el paseante de d'Halmar, lo que había 
habido entre Davis y París era “íntimo” (12). "Él sabía que era uno de los obsesionados por la ciudad tentacular. Y reconocía dolorosamente pertenecer a ese número, podría llamarse de los hechizados de París, que [en otras partes] se sienten como anulados para la simple existencia humana” (12). "Baudelaire lo había dicho: 'Encore a plupart n'ont ils jamais connu, / la douceur du foyer et n'ont jamais vécu!'” (12-13). "Ciudad inmortal, la imperiosa querida que nos impide formar familia" (13); la que no envejece y "cuando nos abandonaba la juventud, a su turno nos abandonaba para dejarse conquistar por los nuevos embrujados" (13). "La ciudad alucinante, sentida y vivida por tantos hombres que ya no son, se precisaba por un momento con todo ese su sortilegio que parece flotar y respirarse en su atmósfera" (13).

Davis, detenido en la remembranza dolorosa de una ciudad que ya lo ha abandonado al igual que la propia juventud, aquella "edad en que uno desestima el fugitivo instante, porque cree que millares como él volverán en nuestra existencia" (16), "rememoraba sus noches enteras de vagar por esa urdimbre de fuego, esencialmente nocturna, cuyo nombre no se pronuncia con los labios" (16). París era no solo la ciudad eterna, no solo la Atenas contemporánea, era la hoguera fantástica donde el caminante, como Moisés sobre la zarza ardiente, tiene alguna experiencia de la divinidad. $\mathrm{Su}$ andar no era simplemente una distracción nocturna en búsqueda de sentimientos, amores o placeres, sino un "divagar en medio del cual había vivido [...] las únicas horas que podía contar como vivientes". Allí, contradictoriamente con su carácter taciturno, "sólo se hallaba plenamente dueño de sí mismo, en medio de la muchedumbre" (16). Sujeto lábil y disperso, "sólo lograba concentrarse cuando pasaba a ser un átomo del todo, en ese prodigioso acumulador de energía que es la ciudad de las ciudades" (16). Había recibido lo que para Baudelaire era el don de "gozar de la muchedumbre", que es "un arte" no concedido a todos, como "[n] o a todos les es dado tomar un baño de multitud" (Baudelaire 387). Es el valor de la calle que, en palabras de Kracauer, "no sólo es el conjunto de impresiones fugaces y de encuentros casuales, sino el sitio donde el flujo de la vida ha de autoafirmarse" (ctd. por Cuvardic García 215).

La evocación de su experiencia parisina juvenil conduce a Davis, en medio del mar (esa especie de anverso silencioso de la multitud urbana), a una antigua noche en que, en medio de la muchedumbre de París, logra sentir “[u]na voz ni viril ni afeminada, de un timbre casi inédito, a la vez velado y vibrante; voz melancólica y gaya a un mismo tiempo, 
con inflexiones de una dulzura felina" (19). El que marchaba delante de Davis, iba "entre dos personas, una mujer y un hombre, y era él mismo un mancebo" (19) que, por su belleza llegaba a ser "uno de esos frutos increíbles que suelen producir las viejas razas" (19) y representaba, por sí mismo, "el producto del asfalto, la flor de ese invernáculo humano que viene a ser la Ciudad, el 'artículo de París', inconfundible e inimitable" (19). En ese joven andrógino, descrito abundantemente en su perfección, casi como un sujeto de otro tiempo, con semejanzas descriptivas al joven Tadrio de Muerte en Venecia, aunque al parecer más adulto y más dueño de sí mismo que el personaje de Thomas Mann, Davis percibe una gran identificación. Dariel -que así se llamaba-incluso reconoce en él a "un hombre de la misma especie en el reino de las afinidades" (25) lo cual ha de pensarse que, dado el contexto, sugiere, más que cualquier otro tipo de cercanía, una identidad de género. Dariel y Davis pasan la noche juntos hasta que los sorprende el alba bajando por Montmartre. Para entonces, Dariel "mostraba el aspecto adolorido de un príncipe que, víctima de un maleficio, vuelve a convertirse en ser inferior hasta que la noche le devuelva su prestigio” (27).

Desde aquel "acontecimiento-conocimiento", Dariel se convierte en conductor de Davis “a través de la noche de París” (28), "[e]ra Virgilio, el divino cicerone, comentando el infierno al visitante humano" (28), “[p]or sus ojos miraban la gran ficción que viene a ser el París noctámbulo, todos los seres que la habían vivido o que simplemente habían soñado con ella" (28-29). Dariel era "el alma de la muchedumbre", era aquel por quien, para Davis, había representado también "el alma encantadora de París" ... era la flor que el personaje había tocado en su juventud y que, años después, regresando a París, ya no podría encontrar porque aquel ser fantasmagórico había muerto joven. Sin embargo,

desde entonces, Davis, cada vez que ha pasado por París, ha visto surgir en el momento álgido de la noche, en el punto céntrico en que hacen remolino todas las corrientes humanas, como el alma en pena de la muchedumbre, la figura de Dariel, como el fantasma de su propia juventud. [...] Él era el fiat, el andrógino de los ojos verdes, el gato-esfinge de la ciudad electrizada y felina. Nadie que no lo haya encontrado, podrá comprenderla nunca. (31) 


\section{Conclusiones}

Con propiedad se pueden reconocer los elementos que caracterizan la flanerie de Augusto d'Halmar con rasgos similares a los que Dorde Cuvardic García califica de "callejeo impresionista" hablando de la flanerie de Arturo Ambrogi, escritor y cronista salvadoreño. En efecto, estos dos creadores modernistas, coincidentes en temas, lugares y trabajos, aunque no en una presumible relación de amistad, se los encuentra describiendo sus viajes con términos y procedimientos similares.

D'Halmar va a trabajar a París como corresponsal de guerra. Sin embargo, la guerra, como objeto formal de sus crónicas, pierde figuración significativa para dar paso a su real interés, es decir, el protagonismo que confiere con generosidad a París, la ciudad que, hacia 1916, había escogido como su destino definitivo.

Se ha intentado establecer una distinción entre "vagamundos" y "paseante". La primera flanerie d'halmariana (no trabajada aquí) tiene que ver con sus grandes viajes previos a París; en ellos es un viajero cosmopolita, un "vagamundos". La segunda flanerie responde a la que desarrolla al interior de la ciudad. El flâneur que se identifica con uno de los personajes peripatéticos de la modernidad decimonónica, el paseante de Baudelaire y de Benjamin.

El cronista, paseante y narrador, se permite observar la ciudad, sus iglesias, sus parques, sus monumentos e, incluso, escaparse de ella momentáneamente en un vuelo que lo conduce a las ponderaciones prometeicas de la las posibilidades de la era moderna. Sin embargo, es en la muchedumbre nocturna en donde termina encontrando "el alma encantadora" de París.

Llegado a este punto, es necesario transitar del soporte "crónica" al de "cuento" para profundizar los alcances de lo que significa el caminante en la noche parisiense. Y precisamente aquí es donde se produce el gran giro que diferencia a d'Halmar de otros intelectuales latinoamericanos recorriendo París. Lo hace porque, en el fondo, el paseo nocturno por la ciudad iluminada, más allá del epidérmico contacto con la diferencia efervescente de la multitud, significa un proceso de encuentro y de identificación con la otredad que oculta el caminante, es decir, con su identidad de género, con su masculinidad disidente, con la identificación amorosa que solo puede darse en esa "ciudad tentacular", donde el gato-esfinge le permite evocar el 
concierto exotista en que se estableció otra suerte de conexiones en el mismo sentido. Así, el simple discurso del paseante en su performance descomprometida del vagar se convierte en d'Halmar en una de las claves para entender la travesía que acomete por el territorio del homoerotismo en la literatura.

\section{Referencias bibliográficas}

Arriagada, Julio y Hugo Goldsack. Augusto D'Halmar. Tres ensayos esenciales y una antología. Santiago de Chile, Ministerio de Educación Pública, 1963.

Baudelaire, Charles. "Las multitudes". Obra Completa. Madrid, Ediciones Akal, 2003.

Benjamin, W. Sobre algunos temas en Baudelaire. Buenos Aires, Leviatán, 1999.

Cuvardic García, Dorde. El flâneur en las prácticas culturales, el costumbrismo y el modernismo. París, Ediciones Publibook, 2012.

D’Halmar, Augusto. “Desde París”. La Unión, Santiago de Chile, 9 Oct. 1917.

. "El frío de París”. La Unión, Santiago de Chile, 18 Mayo 1918.

"El invierno de 1917 en París". La Unión, Santiago de Chile, 24 Jun. 1917.

“El hogar y la guerra I”. La Unión, Santiago de Chile, 17 Oct. 1917. “El París de la guerra”. La Unión, Santiago de Chile, 27 Dic. 1916.

. "El París musical”. La Unión, Santiago de Chile, 20 Jun. 1918.

. “La primavera de París”. La Unión, Santiago de Chile, 25 Sep. 1917.

. Los Alucinados. Santiago de Chile, Ediciones Ercilla, 1935.

. “Los jardines de París”. La Unión, Santiago de Chile, 18 Ene. 1918.

. “Los ruidos de Madrid”. Informaciones, Madrid, 24 Feb. 1927.

. “Nuestra Señora de París”. La Unión, Santiago de Chile, 14 Jun. 1917.

Recuerdos olvidados. Santiago de Chile, Editorial Nascimento, 1975.

"Una existencia parisiense". La Unión, Santiago de Chile, 6 Dic. 1917. 
"Vagamundos, vagabundos y vagos". Informaciones, Madrid, 17 Jun. 1930.

“Vagando por París”. La Unión, Santiago de Chile, 3 Oct. 1917. . "Volando". La Unión, Santiago de Chile, 10 Oct. 1917.

Larraín, Jorge. "La trayectoria latinoamericana a la modernidad". Estudios Públicos, no. 66, otoño 1977, pp. 313-333.

Oróstegui, Daniela. "Lecturas y escrituras de la memoria: narraciones de la experiencia en Walter Benjamin”. Logos: Revista de Lingüística, Filosofía y Literatura, vol. 25, no.1, Universidad de la Serena, pp. 53-64.

Subercaseaux, Benjamín. Chile o una loca geografía. 1938. Santiago de Chile, Editorial Universitaria, 2005, p. 122. 